\title{
Intensive treatment with methotrexate in early rheumatoid arthritis: aiming for remission. Computer Assisted Management in Early Rheumatoid Arthritis (CAMERA, an open-label strategy trial)
}

\author{
S M M Verstappen, J W G Jacobs, M J van der Veen, A H M Heurkens, Y Schenk, E J ter Borg, \\ A A M Blaauw, J W J Bijlsma, on behalf of the Utrecht Rheumatoid Arthritis Cohort study group
}

See end of article for authors' affiliations

Correspondence to:

Dr J W G Jacobs, University Medical Center Utrecht, Department of

Rheumatology \& Clinical Immunology, F02.127, PO

Box 85500, 3508 GA

Utrecht, the Netherlands;

j.w.g.jacobs@umcutrecht.nl

Accepted 17 May 2007

Published Online First

22 May 2007
Background: To investigate whether intensive treatment with methotrexate (MTX) according to a strict protocol and a computerised decision program is more beneficial compared to conventional treatment with MTX in early rheumatoid arthritis.

Methods: In a two-year multicentre open label strategy trial, 299 patients with early rheumatoid arthritis were randomly assigned to the intensive strategy group or the conventional strategy group. Patients in both groups received MTX, the aim of treatment being remission. Patients in the intensive treatment group came to the outpatient clinic once every month; adjustment of the MTX dosage was tailored to the individual patient on the basis of predefined response criteria, using a computerised decision program. Patients of the conventional strategy group came to the outpatient clinic once every three months; they were treated according to common practice. Cyclosporine was added if patients had an inadequate response to maximal tolerated MTX doses. Results: Seventy six (50\%) patients in the intensive strategy group achieved at least one period of remission during the two year trial, versus 55 patients $(37 \%)$ in the conventional strategy group $(p=0.03)$. Areas under the curve for nearly all clinical variables were significantly lower-that is, there was a better clinical effect for the intensive treatment group compared with the conventional treatment group.

Conclusion: The results of this study show that it is possible to substantially enhance the clinical efficacy early in the course of the disease by intensifying treatment with MTX, aiming for remission, tailored to the individual patient. Furthermore, participating rheumatologists indicated that the computerised decision program could be a helpful tool in their daily clinical practice.
$\mathrm{R}$ heumatoid arthritis is a chronic inflammatory disease with heterogeneity in disease activity as well as joint damage, but almost all patients develop disability in the long run. Disease-modifying anti-rheumatic drugs (DMARDs) are started very early after disease onset, because this has proven to be more beneficial than a delayed start. ${ }^{1-4}$ A recent paradigm shift is to aim therapeutically for remission, instead of mere improvement in symptoms and signs. ${ }^{5-7}$ To reach this goal, treatment is intensified by combining various DMARDs, ${ }^{38}$ including biological agents. ${ }^{9-12}$ Methotrexate (MTX) is usually selected as initial therapy and as an anchor drug in combination therapies. ${ }^{13}$ The question is whether an optimally intensified treatment strategy with MTX results in higher remission rates compared to the conventional therapeutic approach with MTX.

In daily clinical practice, therapy choices and dose adjustments are based on the overall view of the individual rheumatologist. Disease activity is often determined "ad hoc" on the basis of a few objective and subjective clinical variables, because time at the outpatient clinic is precious. However, patients with rheumatoid arthritis who seem to be doing well at first glance often show more signs of disease activity when a full joint examination is performed. Repeated assessment of a core set of variables with feedback on previous scoring does not automatically result in intensified treatment however. ${ }^{14}$ With the help of a computerised decision system and a predefined protocol, the goal of remission might be attainable. The advantage of such a decision system is that because assessments and decisions about treatment procedures are standardised, interpretation of the outcome is less susceptible to bias.

The purpose of this trial was to investigate whether an intensive treatment strategy with MTX, according to a strict protocol dictated by a computerised decision program, is more beneficial in terms of the number of patients in remission compared with a conventional treatment strategy approach with MTX.

\section{PATIENTS AND METHODS}

From 1999-2003, all early rheumatoid arthritis patients (disease duration <1 year) who fulfilled the 1987 revised American College of Rheumatology (ACR) criteria for rheumatoid arthritis ${ }^{15}$ were asked to participate in this two-year randomised, open-label prospective multicentre strategy trial. Patients visited the outpatient clinic of one of the six rheumatology departments in the region of Utrecht, the Netherlands, collaborating in the Utrecht Rheumatoid Arthritis Cohort study group. Inclusion criteria were: symptoms $<1$ year and age $>16$ years. Exclusion criteria were: previous use of glucocorticoids or any DMARD, use of cytotoxic or immunosuppressive drugs within a period of three months before inclusion, alcohol abuse ( $>2$ units per day), and psychological problems which would make adherence to the

Abbreviations: ACR, American College of Rheumatology; DMARDs, disease-modifying anti-rheumatic drugs; ESR, erythrocyte sedimentation rate; MTX, methotrexate; NSAIDs, non-steroidal anti-inflammatory drugs; VAS, visual analogue scale 
study protocol impossible. At baseline all patients were monitored for medical conditions that could interfere with MTX usage. This screening included a chest $x$ ray, liver enzymes (AST and ALT), albumin, hepatitis serology, serum creatinine and complete blood count. An independent person performed randomisation in blocks of nine per hospital. The medical ethics committees of all participating hospitals approved this study, and all patients gave written informed consent before entering the study.

\section{Power calculation}

A sample size of 100 patients per group was needed based on a difference in functional disability score of 0.25 (SD 0.7), with a power of $0.80(\beta=0.2)$ and alpha of 0.05 . It is estimated that in daily practice during the first two years of treatment approximately $30 \%$ of patients need to discontinue MTX because of inefficacy or adverse events. ${ }^{16}$ We therefore included 150 patients in each strategy group.

\section{Treatment}

Patients were randomly allocated to one of two strategy groups: the conventional strategy group or the intensive strategy group. The starting dose of oral MTX was $7.5 \mathrm{mg} /$ week. In both groups, the dosage of MTX was not changed if patients had responded compared with the previous visit (fig 1); otherwise the dosage was increased stepwise by $5 \mathrm{mg} /$ week, to a maximum of $30 \mathrm{mg} /$ week. If the maximum (tolerable) dose of MTX was reached and patients did not fulfil the criteria for sustained response (fig 1), MTX was administered subcutaneously (sc). For patients on MTX sc having an inadequate response, cyclosporine was added to the MTX, while the dosage of MTX was reduced to $15 \mathrm{mg} /$ week (fig 1 ). The starting dose of cyclosporine was $2.5 \mathrm{mg} / \mathrm{kg} / \mathrm{day}$; this was increased stepwise by $0.5 \mathrm{mg} /$ $\mathrm{kg} /$ day to a maximum of $4 \mathrm{mg} / \mathrm{kg} /$ day, if no response was reached. If patients fulfilled the criteria for sustained response, MTX was reduced stepwise by $2.5 \mathrm{mg} /$ week as long as patients met these criteria; otherwise the dose of MTX was continued or increased again according to protocol.

Folic acid was prescribed to every patient ( $0.5 \mathrm{mg} /$ day $)$. Use of non-steroidal anti-inflammatory drugs (NSAIDs) was allowed in both strategy groups. Intra-articular injections were avoided in so far as possible because this might lead to bias with respect to treatment effect between the two treatment groups. Oral glucocorticoids were not allowed during the trial unless unavoidable, which then had to be approved by another rheumatologist participating in this study.

\section{Conventional strategy group}

Patients in this strategy group visited the outpatient clinic once every three months and were treated according to protocol. This strategy, which comprised dose adjustments based on the opinion of the individual rheumatologist at threemonthly visits, was similar to common practice in the Netherlands in 1998 when this study was designed. The minimum time to reach the highest dose of $30 \mathrm{mg} /$ week MTX was 52 weeks.

\section{Intensive strategy group}

The strategy approach in the intensive strategy group differed in three ways from that of the conventional strategy group, namely:

1. The use of a computer decision program (designed by JWG Jacobs). At each visit, data on swollen joint count, tender joint count, erythrocyte sedimentation rate (ESR), and visual analogue scale (VAS) for general well-being were entered by the rheumatologist. The program then calculated whether or not predefined criteria of response to treatment were met. As
ESR values were only known the next day, the participating rheumatologists informed their patient the following day by telephone whether a dose change was necessary or not.

2. The response criteria (fig 1 ).

3. The frequency of evaluations leading to therapeutic decisions; fast step-up and fast step-down of MTX dosage.

Patients in the intensive strategy group came to the outpatient clinic once every four weeks and the maximum dose of $30 \mathrm{mg} /$ week MTX could be reached after 18 weeks.

\section{Clinical variables}

At baseline and at the predefined assessment points, depending on the strategy group, the following clinical variables were assessed: ESR $\left(\mathrm{mm} / \mathrm{h}^{1 s t}\right)$, number of swollen joints $(0-38)$, number of tender joints (0-38), VAS for pain (mean score of VAS pain at night and VAS pain in the morning, 0-100 $\mathrm{mm}=$ most pain), VAS general well-being (0-100 $\mathrm{mm}=$ worst score $)$, and morning stiffness $(0-180 \mathrm{~min})$. The Dutch version of the Health Assessment Questionnaire $\left(\mathrm{HAQ},{ }^{17}\right)$ was filled out every three months $(0-3=$ most functional disability). Rheumatoid factor status was defined to be positive or negative according to the latex fixation test or the Waaler-Rose test (positive $>20 \mathrm{U} / \mathrm{l}$ ) at baseline. Radiographs of hands and feet were taken at inclusion, at one, and at two years. Radiographs were independently scored in chronological order according to the modified Sharp/van der Heijde method (range $0-448^{18}$ ) by two investigators who were blinded for the treatment strategy.

\section{Clinical efficacy and radiographic progression}

The primary major outcome of this study was the number of patients in remission for at least three months at any time during the two year trial. Remission was defined as: no swollen joints, and at least two out of three of the following criteria: number of tender joints $\leqslant 3$, ESR $\leqslant 20 \mathrm{~mm} / \mathrm{h}^{1 \mathrm{st}}$ and VAS general well-being $\leqslant 20 \mathrm{~mm}$; for both groups these criteria data were analysed at the same three month intervals.

Second major outcome was the area under the curve (AUC) standardised to time calculated for all clinical variables. ${ }^{19} 20$ The mean score of the previous and the next score imputed missing data between two visits. For $21 \%$ of the patients, functional disability scores were missing at baseline and these score were imputed by the mean baseline score of the strategy group.

Additionally, we calculated the mean change in disease activity at one and at two years and the individual patient improvement from baseline according to modified ACR50 criteria, because we did not measure VAS physician's global assessment. These latter criteria were met if patients had a 50\% improvement in both number of swollen and tender joints and a $50 \%$ improvement in two out of four of the following variables: ESR, VAS pain, VAS general well-being, and functional disability.

\section{Adverse events and medication-related toxicity}

In both strategy groups, all adverse events were evaluated and recorded at every visit according to a predefined protocol. Liver toxicity was defined as an increase of transaminase enzymes (AST, ALT) above the upper limit of normal. Haematological abnormalities were defined as: anaemia $(\mathrm{Hb}<6.5 \mathrm{mmol} / \mathrm{l})$, leucopenia $\left(<3.5^{*} 10^{9} / 1\right)$, thrombopenia $\left(<150^{*} 10^{9} / 1\right)$, pancytopenia (two out of three of these criteria), and other. Post-dosing reactions were defined as reactions which occurred within $24 \mathrm{~h}$ after MTX intake (for example, arthralgia). Criteria for dose adjustments or discontinuation of MTX use because of adverse events were dictated by the study protocol. 


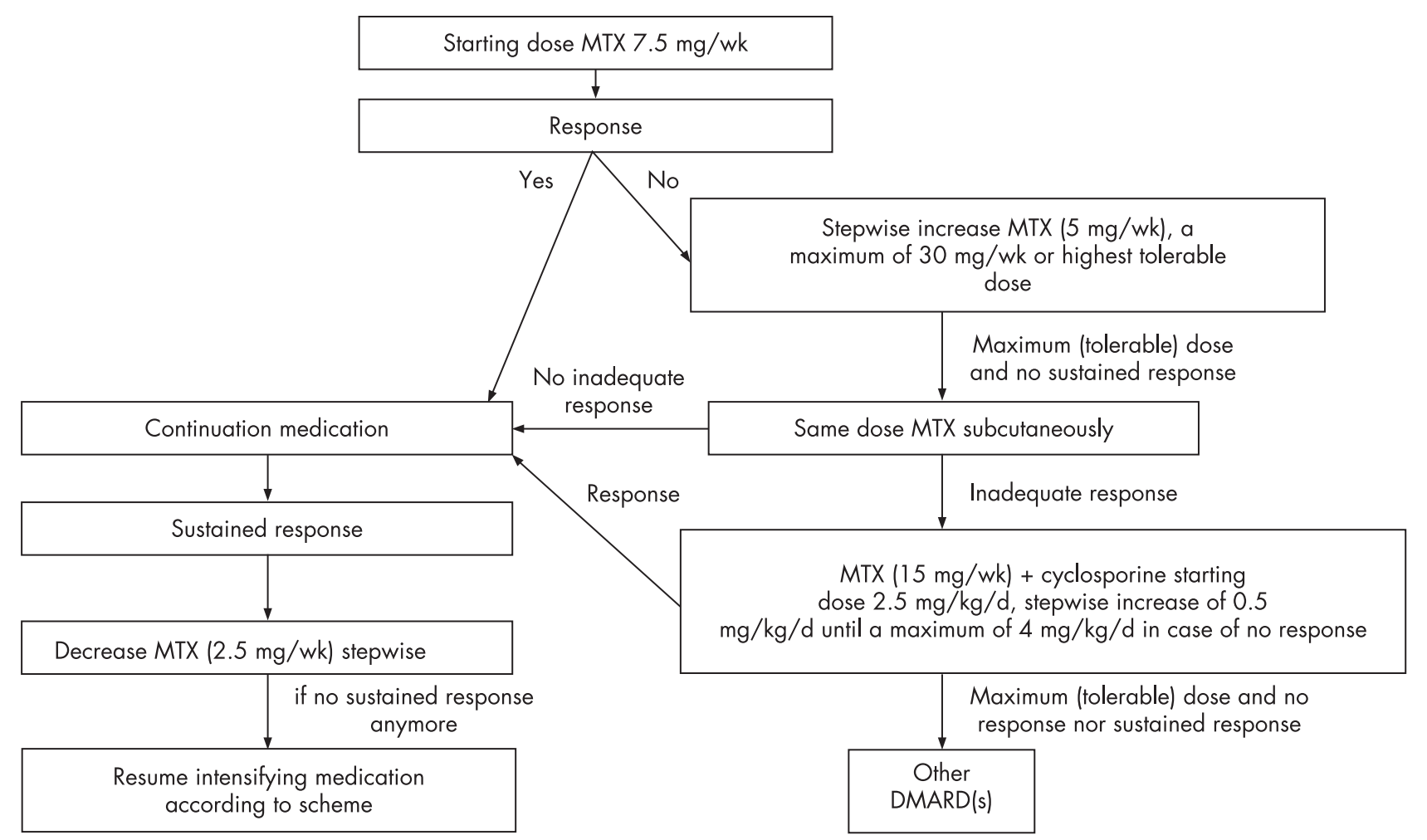

\begin{tabular}{|c|c|c|c|}
\hline & $\begin{array}{c}\text { Response } \\
\text { compared to previous visit: }\end{array}$ & Inadequate response & Sustained response \\
\hline Intensive strategy group & $\begin{array}{l}>20 \% \text { improvement of number of } \\
\text { swollen joints and } \\
>20 \% \text { improvement in } 2 \text { out of } 3 \\
\text { criteria: ESR, number of tender joints, } \\
\text { and VAS general well-being. }\end{array}$ & $\begin{array}{l}\leqslant 50 \% \text { improvement from baseline for } \\
\text { number of swollen joints and } \leqslant 50 \% \\
\text { improvement from baseline for } 2 \text { out } \\
\text { of } 3 \text { variables: ESR, number of tender } \\
\text { joints, and VAS general well-being. }\end{array}$ & \multirow{2}{*}{$\begin{array}{l}\text { No swollen joints and } 2 \text { out of } \\
3 \text { criteria: number of painful } \\
\text { joints } \leqslant 3, E S R \leqslant 20 \mathrm{~mm} / \mathrm{h}^{1 \mathrm{st}} \\
\text { VAS general well being } \leqslant 20 \mathrm{~mm}\end{array}$} \\
\hline $\begin{array}{c}\text { Conventional strategy } \\
\text { group }\end{array}$ & $\begin{array}{l}\text { - Decrease of number of swollen } \\
\text { joints } \\
\text { - If number of swollen joints } \\
\text { unchanged, decision of response } \\
\text { depended on assessors' judgment, } \\
\text { looking at number of tender joints, } \\
\text { ESR, and VAS general well-being. }\end{array}$ & $\begin{array}{l}\text { Number of swollen joints } \geqslant 6, \text { number } \\
\text { of painful joints } \geqslant 3, E S R \geqslant 28 \mathrm{~mm} / \mathrm{h}^{1 \mathrm{st}} \text {, } \\
\text { and morning stiffness } \geqslant 45 \mathrm{~min} \text {. }\end{array}$ & \\
\hline
\end{tabular}

Figure 1 Protocol and response criteria for the intensive and conventional strategy group separately. The sustained response criteria had to be fulfilled for six months (three subsequent visits) in the conventional strategy group and for 12 weeks (four subsequent visits) in the intensive strategy group.

\section{Statistical analyses}

Intention-to-treat analyses were performed, in which the last available data were carried forward. This was not done for radiographic damage because the scores at two years would then be underestimated. Median AUC for all clinical variables and median radiographic progression rate were compared between the two strategy groups using the Mann-Whitney U test. Other continuous variables were tested using the independent $t$ test in the case of normal distribution and Mann-Whitney $U$ test in the case of non-normal distribution. For both remission rates and individual patient improvement rates, patients who had to withdraw in the first year of the study were designated as nonresponder in the first year. Patients who withdrew during the second year, but fulfilled the ACR50 criteria or the remission criteria during the first year, were considered as responders in the first year. For the two-year analyses, all patients who withdrew from the study were considered as non-responders. The $\chi^{2}$ test was used to test differences in remission and responder proportions between the two strategy groups.

For all analyses, the level of significance was set at $\mathrm{p}<0.05$ and tested two-sided using SPSS 12.0.

\section{RESULTS}

Baseline characteristics of the 299 included patients ( 148 in the conventional and 151 in the intensive strategy group) are shown in table 1. During this two-year study, 35 patients in the conventional strategy group and 59 patients in the intensive strategy group withdrew (fig 2). Of these patients, eight in the conventional strategy group and two in the intensive strategy group withdrew shortly after inclusion, but they were included in all analyses. Mean (standard deviation (SD)) time to withdrawal was 57 (SD 28) weeks for patients in the intensive strategy group and 42 (SD 31) weeks for patients of the conventional strategy group $(p=0.02)$. 


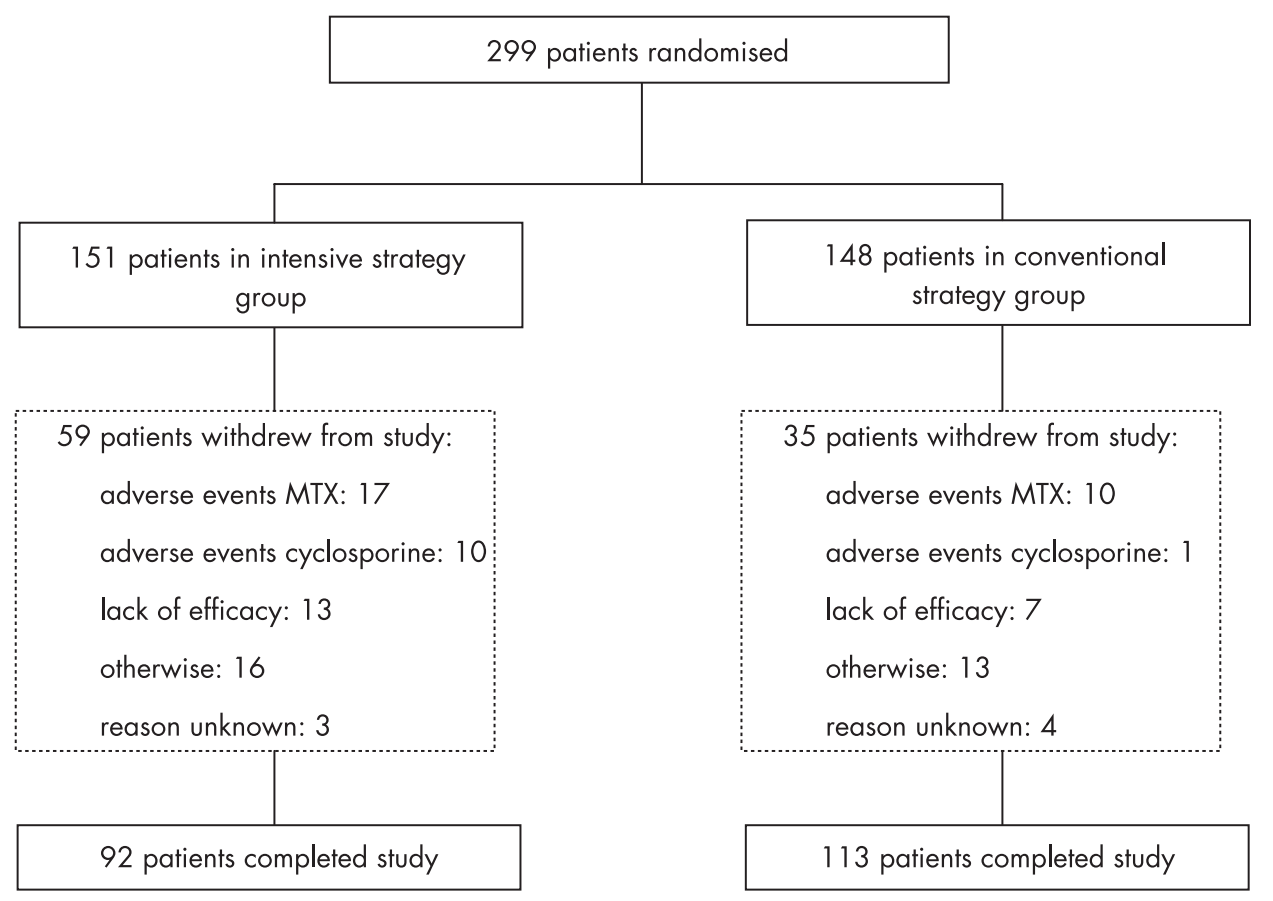

Figure 2 Study population of intensive and conventional strategy group. Reasons for withdrawal "otherwise" included: pregnancy, deceased, moving out of the area, personal problems, etc.

\section{Clinical efficacy and radiographic progression}

The primary outcome was the number of patients in remission for three months at some time during this two year study. In the first year, 53 patients (35\%) of the intensive strategy group achieved at least one period of remission versus 21 patients $(14 \%)$ in the conventional strategy group $(p<0.001)$. Over two years the number of patients in remission was, respectively, 76 patients $(50 \%)$ versus $55(37 \%)(p=0.029)$. Mean $(95 \% \mathrm{CI})$ time until the first period of remission was significantly shorter for the intensive strategy group: 10.4 (9.1 to 11.7) months compared with the conventional strategy group: 14.3 (12.6 to 16.1) months, $\mathrm{p}<0.001$. In addition, the duration of all periods of remission together was significantly longer in the intensive strategy group: 11.6 (10.1 to 13.1) months, compared to the conventional strategy group: 9.1 (7.6 to 10.6) months, $\mathrm{p}=0.025$.

Table 1 Demographic and clinical characteristics at inclusion

\begin{tabular}{lll}
\hline & $\begin{array}{c}\text { Intensive strategy } \\
\text { group, } \mathbf{n = 1 5 1}\end{array}$ & $\begin{array}{l}\text { Conventional strategy } \\
\text { group, } \mathbf{n = 1 4 8}\end{array}$ \\
\hline Women (\%) & $104(69)$ & $97(66)$ \\
Age, years & $54(14)$ & $53(15)$ \\
ESR, mm/h $\mathrm{h}^{\text {st }}$ & $36(27)$ & $39(25)$ \\
Morning stiffness, min & $87(55)$ & $88(54)$ \\
Number of swollen joints & $14(6)$ & $14(6)$ \\
Number of tender joints & $15(7)$ & $14(7)$ \\
VAS general well-being, mm & $54(22)$ & $52(23)$ \\
VAS pain, mm & $51(26)$ & $47(25)$ \\
Rheumatoid factor (\% positive) & $89(66)$ & $77(62)$ \\
Functional ability, HAQ & $1.2(0.7)$ & $1.2(0.7)$ \\
Radiographic damage score & $1.6(4.2)$ & $2.2(5.3)$ \\
\hline
\end{tabular}

ESR, erythrocyte sedimentation rate; VAS, visual analogue scale; $H A Q$, Health Assessment Questionnaire.

Data show mean (SD) for continuous data and number (\%) for categorical data. Ranges of clinical variables are as follows: ESR $\left(2-140 \mathrm{~mm} / \mathrm{h}^{\text {lst }}\right)$; morning stiffness (0-180 min); number of swollen and number of tender joints (0-38); both VAS scales (0-100 $\mathrm{mm}=$ worst score); functional ability (0-3 =worst score); radiographic damage score, modified Sharp/van der Heijde score (0-448). Rheumatoid factor was determined in 135 patients in the intensive strategy group and in 124 patients in the conventional strategy group.
Mean scores of disease activity at three-month intervals are shown in figure $3 \mathrm{~A}-\mathrm{G}$. The intensive strategy approach resulted in statistically significantly lower median $\left(\mathrm{IQ}_{0.25-0.75}\right)$ AUCs for nearly all clinical disease activity parameters compared with the conventional strategy: morning stiffness: 17.0 (7.5 to 41.2$)$ vs 23.7 ( 12.3 to 56.7$), \mathrm{p}=0.009$; ESR: 17.7 ( 10.2 to 27.6 ) vs 21.6 ( 13.0 to 33.6$), p=0.007$; tender joint count: 3.6 (1.9 to 6.0 ) vs 5.5 (2.8 to 9.2), $\mathrm{p}<0.001$; swollen joint count: 2.7 ( 1.5 to 5.2 ) vs 4.7 (2.8 to 7.6 ), $\mathrm{p}<0.001$; VAS general well-being: 19.0 ( 11.5 to 35.4 ) vs 31.2 ( 16.2 to 44.6 ); $\mathrm{p}<0.001$, VAS pain: 12.0 (5.0 to 24.3 ) vs 19.0 (9.5 to 34.1), $\mathrm{p}=0.001$; and functional disability: 0.64 ( 0.3 to 1.3$)$ vs 0.80 ( 0.3 to 1.2$), p=0.8$. All clinical variables improved statistically significantly in the first year in the intensive strategy group when compared to the conventional strategy group, with the exception of ESR, morning stiffness and functional disability (table 2). Clinical and functional changes from baseline were similar between the two groups at two years.

The modified ACR50 criteria at one and at two years were reached in, respectively, 87 patients (58\%) and $69(46 \%)$ in the intensive strategy group and 64 patients (43\%) and $67(45 \%)$ in the conventional strategy group $(p=0.018$ at one year and $\mathrm{p}=1.00$ at two years).

At two years, radiographs of 90 (98\%) completers in the intensive strategy group and of 109 (97\%) completers in the conventional strategy group were available; median ( $\left.\mathrm{IQ}_{0.25-0.75}\right)$ annual radiographic progression over two years was 0 ( 0 to 2.0) (mean $1.9,95 \%$ CI 1.0 to 2.7 ) units/year versus 0 (0 to 2.5 ) (mean $2.1,95 \%$ CI 1.3 to 2.8 ) units/year $(p=0.9)$, respectively. The cumulative probability plot (fig $3 \mathrm{H}$ ) shows that in both strategy groups approximately $50 \%$ did not progress over two years, but for the other $50 \%$ the progression rate was higher in the conventional strategy group than in the intensive strategy group.

\section{Medication}

For completers, the mean (95\% CI) dose of MTX was $16.1 \mathrm{mg}$ / week (14.8 to 17.3) for the intensive strategy group versus $14.0 \mathrm{mg} /$ week (13.1 to 14.8 ) for the conventional strategy group, mean (95\% CI) difference 2.1 (0.6 to 3.6), $\mathrm{p}=0.008$. Mean (SD) maximum dose MTX, excluding those patients who 
A
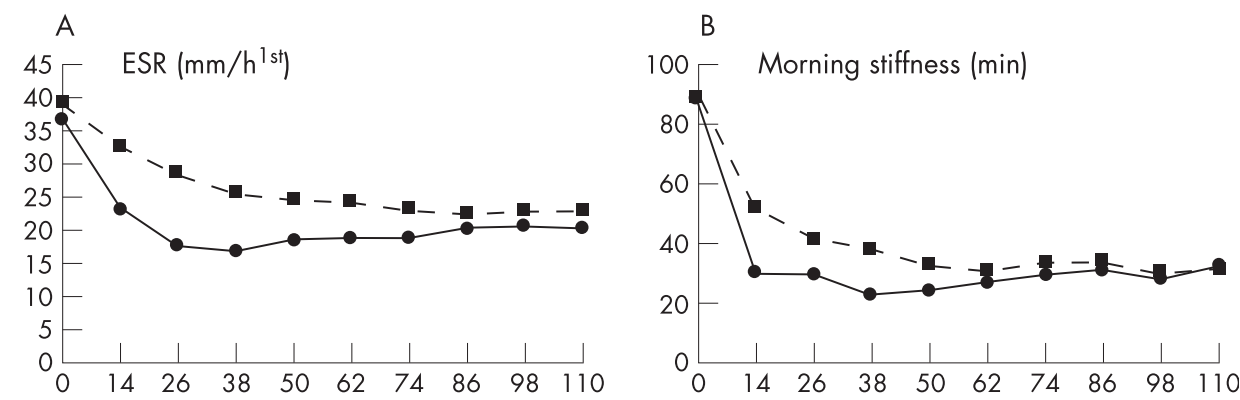

C

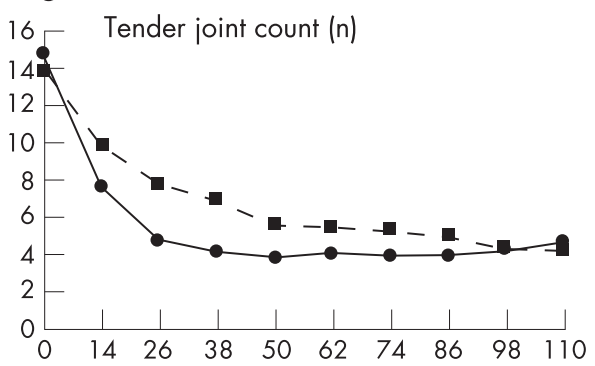

$\mathrm{E}$

$60\ulcorner$ VAS general well-being $(\mathrm{mm})$

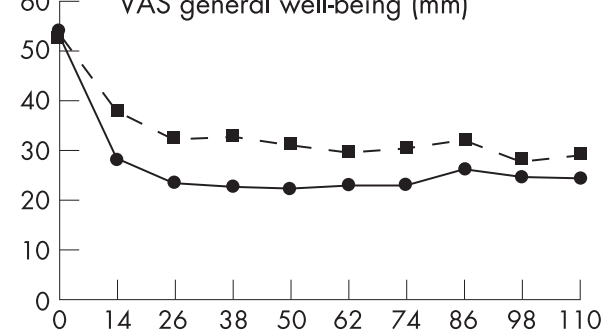

$\mathrm{G}$

$1.4\lceil\quad$ Functional disability (HAQ)

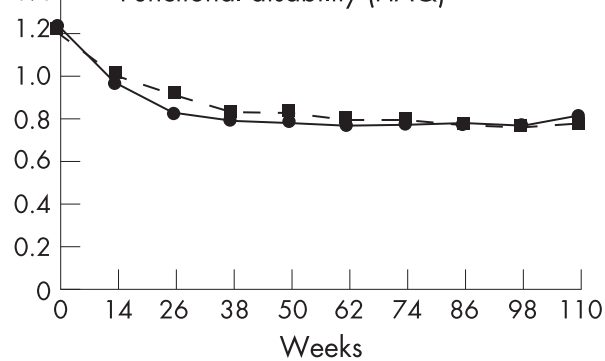

D

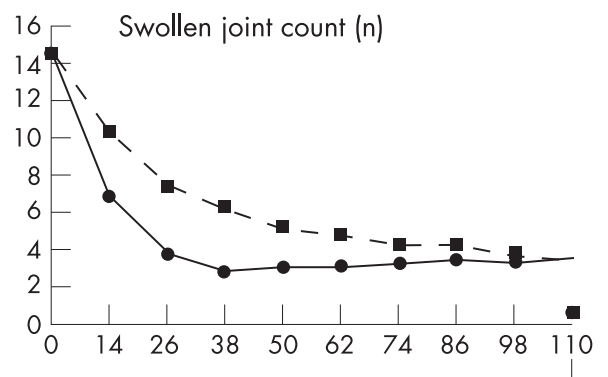

$\mathrm{F}$
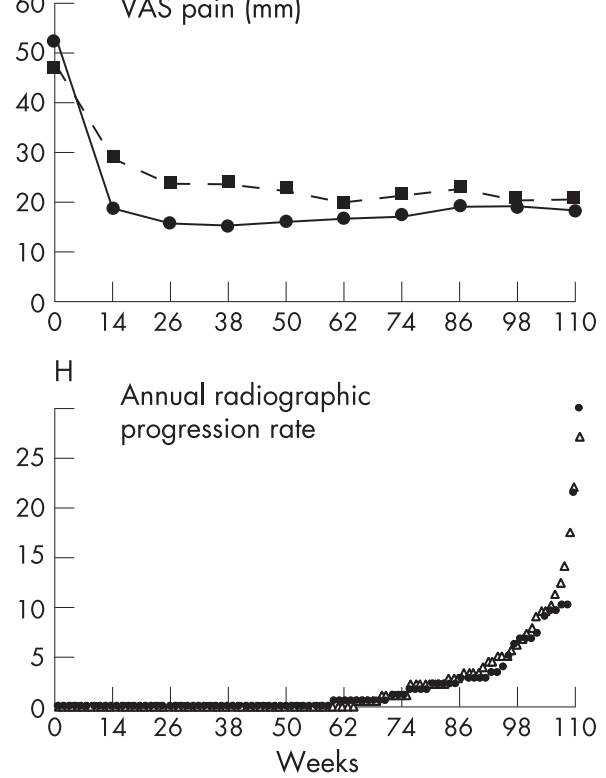

Figure 3 (A-G) Mean scores over time for all clinical variables for the intensive strategy group (solid line) and the conventional strategy group (dotted line). Ranges of clinical variables are as follows: ESR $\left(2-140 \mathrm{~mm} / \mathrm{h}^{1 \mathrm{st}}\right)$; morning stiffness (0-180 min); number of swollen and number of tender joints (0-38); both VAS scales (0-100 $\mathrm{mm}=$ worst score), and functional disability $(0-3=$ worst score). (H) The cumulative probability plot for the annual radiographic progression rate over two years for completers of the intensive strategy group (black dots) and completers of the conventional strategy group (open triangles). withdrew shortly after inclusion, in the intensive strategy group was 24.9 (6.5) mg/week MTX versus 18.2 (6.5) mg/week MTX in the conventional strategy group. For completers who fulfilled the criteria of remission versus those who did not, respectively, the mean (SD) dose of MTX over two years was $15.3 \mathrm{mg} /$ week (6.1) versus $19.7 \mathrm{mg} /$ week (4.7) $(\mathrm{p}=0.008)$ in the intensive strategy group and $11.8 \mathrm{mg} /$ week (4.3) versus $16.1 \mathrm{mg} /$ week (4.1) $(\mathrm{p}<0.01)$ in the conventional strategy group. In the total study population, the average (SD) cumulative dose MTX until the start of the first period of remission was 892 (588) $\mathrm{mg}$ in the intensive strategy group and 776 (506) $\mathrm{mg}$ in the conventional strategy group $(p=0.243)$. The number of patients that converted to MTX administration sc because of achieving the maximum dose of oral MTX or because of toxicity reasons was 55 in the intensive strategy group and 12 in the conventional strategy group.

In the intensive strategy group and conventional strategy group, cyclosporine was given to 38 and 4 patients respectively as a next step after the maximum (tolerable) dose of MTX was reached. Six patients in the intensive strategy groups used cyclosporine at start of the first remission period versus none in the conventional strategy group.

From six months on, statistically significantly fewer patients in the intensive strategy group used NSAIDs compared to the conventional strategy group ranging from, respectively, 79\% versus $93 \%$ at six months $(p=0.002)$ to $46 \%$ versus $71 \%$ at two years $(p<0.001)$. At least one intra-articular injection was administered to $41(27 \%)$ of the patients in the intensive strategy group and to $37(25 \%)$ in the conventional strategy group, $\mathrm{p}=0.8$.

\section{Adverse events}

Among $87 \%$ of the patients in the conventional strategy group, during one of the 1132 protocolised visits after MTX start a total of 873 adverse events occurred. In the intensive strategy group, $94 \%$ of the patients had a total of 2378 adverse events during 3190 assessments. The type of adverse events and the percentage of total number of adverse events in the intensive strategy group versus the conventional strategy group, respectively, were: gastrointestinal (24.6\% vs $25.2 \%)$; mucocutaneous 
Table 2 Change from baseline for clinical variables after one and after two years

\begin{tabular}{|c|c|c|c|c|c|c|}
\hline & \multicolumn{3}{|l|}{1 year } & \multicolumn{3}{|l|}{2 years } \\
\hline & $\begin{array}{l}\text { Intensive } \\
\text { strategy group }\end{array}$ & $\begin{array}{l}\text { Conventional } \\
\text { strategy group }\end{array}$ & $\begin{array}{l}\text { Mean }(95 \% \mathrm{Cl}) \text { difference } \\
\text { between strategy groups }\end{array}$ & $\begin{array}{l}\text { Intensive } \\
\text { strategy group }\end{array}$ & $\begin{array}{l}\text { Conventional } \\
\text { strategy group }\end{array}$ & $\begin{array}{l}\text { Mean }(95 \% \mathrm{Cl}) \text { difference } \\
\text { between strategy groups }\end{array}$ \\
\hline \multicolumn{7}{|l|}{$\mathrm{ESR}, \mathrm{mm} / \mathrm{h}^{1 \mathrm{st}}$} \\
\hline All patients & $-18(27)$ & $-15(24)$ & $-3(-9$ to 2$)$ & $-16(27)$ & $-16(24)$ & $-0.3(-6$ to 5$)$ \\
\hline Completers & $-24(27)$ & $-16(24)$ & $-7(-15$ to -0.4$)$ & $-22(27)$ & $-19(24)$ & $-3(-10$ to 4$)$ \\
\hline \multicolumn{7}{|c|}{ Morning stiffness, min. } \\
\hline All patients & $-63(61)$ & $-56(59)$ & $-7(-21$ to 6$)$ & $-56(68)$ & $-57(63)$ & $1(-13$ to 16$)$ \\
\hline Completers & $-73(56)$ & $-64(57)$ & $-9(-25$ to 7$)$ & $-60(70)$ & $-69(60)$ & $8(-10$ to 26$)$ \\
\hline \multicolumn{7}{|c|}{ Number of swollen joints } \\
\hline All patients & $-11(8)$ & $-9(7)$ & $-2(-4$ to -1$)$ & $-11(8)$ & $-11(8)$ & $-0.3(-2 ; 2)$ \\
\hline Completers & $-14(7)$ & $-10(8)$ & $-3(-5$ to -1$)$ & $-13(7)$ & $-13(7)$ & $-0.4(-2 ; 2)$ \\
\hline \multicolumn{7}{|c|}{ Number of tender joints } \\
\hline All patients & $-11(7)$ & $-8(8)$ & $-3(-6$ to -1$)$ & $-10(9)$ & $-9(8)$ & $-1(-3$ to 1$)$ \\
\hline Completers & $-13(8)$ & $-9(8)$ & $-4(-6$ to -1$)$ & $-12(9)$ & $-11(8)$ & $-1(-4$ to 1$)$ \\
\hline \multicolumn{7}{|c|}{ VAS general well-being, $\mathrm{mm}$} \\
\hline All patients & $-32(29)$ & $-21(29)$ & $-11(-17$ to -4$)$ & $-30(31)$ & $-22(28)$ & $-8(-15$ to -1$)$ \\
\hline Completers & $-38(27)$ & $-24(29)$ & $-14(-22$ to -6$)$ & $-37(29)$ & $-28(27)$ & $-9(-16$ to -1$)$ \\
\hline \multicolumn{7}{|l|}{ VAS pain, mm } \\
\hline All patients & $-36(31)$ & $-24(30)$ & $-11(-18$ to -4$)$ & $-34(31)$ & $-26(31)$ & $-9(-16$ to -1$)$ \\
\hline Completers & $-42(27)$ & $-27(30)$ & $-15(-23$ to -7$)$ & $-40(28)$ & $-30(28)$ & $-10(-18$ to -2$)$ \\
\hline \multicolumn{7}{|c|}{ Functional disability, $\mathrm{HAQ}$} \\
\hline All patients & $-0.44(0.59)$ & $-0.39(0.66)$ & $-0.05(-0.19$ to 0.09$)$ & $-0.41(0.64)$ & $-0.42(0.76)$ & $0.01(-0.15$ to 0.17$)$ \\
\hline Completers & $-0.56(0.53)$ & $-0.49(0.67)$ & $-0.07(-0.24$ to 0.10$)$ & $-0.55(0.62)$ & $-0.54(0.79)$ & $-0.01(-0.20$ to 0.19$)$ \\
\hline
\end{tabular}

$E S R$, erythrocyte sedimentation rate; VAS, visual analogue scale; $H A Q$, Health Assessment Questionnaire.

Data show mean (SD) change from baseline and mean $(95 \% \mathrm{Cl})$ difference between the two treatment strategy groups for the total study population and for completers. For all clinical variables, negative values indicate improvement from baseline.

reaction (14.8\% vs $18.2 \%$ ); neurological disorders ( $18.8 \%$ vs $18.8 \%)$; renal events $(2.4 \%$ vs $2.8 \%)$; liver toxicity $(23.2 \%$ vs $18.6 \%$ ); haematological abnormalities (7.1\% vs $4.2 \%)$; pulmonary symptoms $(2.0 \%$ vs $5.3 \%)$; post-dosing reactions of MTX ( $1.8 \%$ vs $2.1 \%)$; and other adverse events (5.2\% vs $4.8 \%$ ).

\section{DISCUSSION}

In this pragmatic two-year open label trial we evaluated whether an intensive treatment strategy approach with the conventional drug MTX, according to a strict protocol determined by a computerised decision program, was more beneficial than a conventional strategy with MTX in daily practice.

The key message of this paper is that when patients with early rheumatoid arthritis are treated according to an intensive treatment strategy, remission is achieved more often, faster, and for a longer period of time than with a conventional strategy approach. For the intensive strategy group the maximum dose of $30 \mathrm{mg} /$ week could already be reached after 18 weeks. Probably for this reason, the effect of the intensive strategy was most pronounced in the first months after inclusion. This effect is even more striking because fewer patients in the intensive strategy group used NSAIDs compared with the conventional strategy group.

This study shows that it is possible to increase the clinical benefit of MTX by intensifying treatment tailored to the individual patient through frequent evaluation of a core set of variables and the use of a computerised decision program. Such a program increases the objectivity when using response criteria and when applying in an open-label study. In this study, the program was considered easy to use by the participating rheumatologists; we therefore think that it is feasible to introduce it into daily practice.

In our study, a high percentage of patients did not develop joint damage during the two years of follow-up, but radiographic progression was slightly higher in the conventional compared with the intensive strategy group for those patients with progression. It is possible that the lower disease activity over time in the intensive strategy group may only become evident as less radiographic damage later on, as has been shown in other studies. ${ }^{21} 22$

The design of our study is unique and differs on several points from the TICORA study. ${ }^{23}$ In our study, intensification of treatment was based on the percentage change in disease activity from the previous visit in the intensive treatment strategy arm, which was determined in a standardised way by using a computer program, whereas in the TICORA study medication changes were based on the disease activity score (DAS28). We did not use the DAS28 for the evaluation of individual patients, because joints of feet are not included in the DAS28 and it has only been validated as a composite score for groups of patients and not for individual patients. ${ }^{24} 25$ Furthermore, our study protocol also permitted us to reduce the dosage of treatment in $84(56 \%)$ patients in the intensive strategy group because of sustained response, limiting overtreatment of the individual patient. For 31 of these patients dose MTX could even be reduced and stopped.

Although more patients in the intensive strategy group reported adverse events and had to withdraw from this study because of MTX-related adverse events compared to patients in the conventional strategy group, we found that MTX was in general well tolerated, as observed in other studies. ${ }^{26}{ }^{27}$ In order to possibly increase the tolerability of MTX, a higher dose of folic acid could be prescribed when applying an intensive strategy approach in daily practice. Noticeably, a total of 11 patients had to withdraw because of multiple adverse events, including hypertension $(\mathrm{n}=2)$, after the start of cyclosporine.

In conclusion, the results of this strategy study show that it is possible to substantially enhance the clinical benefit early in the course of the disease by intensifying treatment with MTX aiming for remission. Furthermore, based on the opinion of the participating rheumatologists, using the computerised decision program to apply a predefined treatment protocol could also be a helpful tool in daily practice.

\section{ACKNOWLEDGEMENTS}

The authors would like to thank A A Kruize, A W A M van Rijthoven, J C Ehrlich, D M Hofman, G A van Albada-Kuipers, C van BoomaFrankfort, H C M Haanen, and all participating research nurses of the 
Utrecht Rheumatoid Arthritis study group (SRU). They would also like to thank A A van Everdingen for scoring the radiographs.

\section{Authors' affiliations}

S M M Verstappen, J W G Jacobs, J W J Bijlsma, University Medical Center Utrecht, Utrecht, the Netherlands

M J van der Veen, St Jansdal Hospital, Harderwijk, the Netherlands

A H M Heurkens, Meander Medical Center, Amersfoort, the Netherlands Y Schenk, Diakonessenhuis, Utrecht, the Netherlands

E J ter Borg, St Antonius Hospital, Nieuwegein, the Netherlands

A A M Blaauw, Flevo Hospital, Almere, the Netherlands

Competing interests: None declared.

\section{REFERENCES}

1 van der Heide $A$, Jacobs JW, Biilsma JW, Heurkens AH, van Booma-Frankfort $C$, van der Veen MJ, et al. The effectiveness of early treatment with "second-line" antirheumatic drugs. A randomized, controlled trial. Ann Intern Med 1996; 124:699-707.

2 van Jaarsveld CH, Jacobs JW, van der Veen MJ, Blaauw AA, Kruize AA, Hofman DM, et al. Aggressive treatment in early rheumatoid arthritis: a randomised controlled trial. On behalf of the Rheumatic Research Foundation Utrecht, The Netherlands. Ann Rheum Dis 2000;59:468-77.

3 Boers M, Verhoeven AC, Markusse HM, van de Laar MA, Westhovens R, van Denderen JC, et al. Randomised comparison of combined step-down prednisolone, methotrexate and sulphasalazine with sulphasalazine alone in early rheumatoid arthritis. Lancet 1997;350:309-18.

4 Maillefert JF, Combe B, Goupille P, Cantagrel A, Dougados M. Long term structural effects of combination therapy in patients with early rheumatoid arthritis: five year follow up of a prospective double blind controlled study. Ann Rheum Dis 2003;62:764-6.

5 O'Dell JR. Therapeutic strategies for rheumatoid arthritis. N Engl J Med 2004;350:2591-602.

6 American College of Rheumatology Subcommittee on Rheumatoid Arthritis Guidelines. Guidelines for the management of rheumatoid arthritis: 2002 Update. Arthritis Rheum 2002;46:328-46.

7 Emery P, Salmon M. Early rheumatoid arthritis: time to aim for remission? Ann Rheum Dis 1995;54:944-7.

8 Mottonen $T$, Hannonen $P$, Leirisalo-Repo M, Nissila M, Kautiainen H, Korpela M, et al. Comparison of combination therapy with single-drug therapy in early rheumatoid arthritis: a randomised trial. FIN-RACo trial group. Lancet 1999;353:1568-73.

9 Genovese MC, Bathon JM, Martin RW, Fleischmann RM, Tesser JR, Schiff MH, et al. Etanercept versus methotrexate in patients with early rheumatoid arthritis: twoyear radiographic and clinical outcomes. Arthritis Rheum 2002;46:1443-50.

10 Lipsky PE, van der Heijde DM, St Clair EW, Furst DE, Breedveld FC, Kalden JR, et al. Infliximab and methotrexate in the treatment of rheumatoid arthritis. AntiTumor Necrosis Factor Trial in Rheumatoid Arthritis with Concomitant Therapy Study Group. N Engl J Med 2000;343:1594-602.
11 Olsen NJ, Stein CM. New drugs for rheumatoid arthritis. N Engl J Med 2004;350:2167-79.

12 Weinblatt ME, Keystone EC, Furst DE, Moreland LW, Weisman MH, Birbara CA et al. Adalimumab, a fully human anti-tumor necrosis factor alpha monoclonal antibody, for the treatment of rheumatoid arthritis in patients taking concomitant methotrexate: the ARMADA trial. Arthritis Rheum 2003;48:35-45.

13 Jobanputra P, Wilson J, Douglas K, Burls A. A survey of British rheumatologists' DMARD preferences for rheumatoid arthritis. Rheumatology (Oxford) 2004;43:206-10

14 Fransen J, Stucki G, Twisk J, Chamot AM, Gerster JC, Langenegger T, et al. Effectiveness of a measurement feedback system on outcome in rheumatoid arthritis: a controlled clinical trial. Ann Rheum Dis 2003;62:624-9.

15 Arnett FC, Edworthy SM, Bloch DA, McShane DJ, Fries JF, Cooper NS, et al. The American Rheumatism Association 1987 revised criteria for the classification of rheumatoid arthritis. Arthritis Rheum 1988;31:315-24.

16 Alarcon GS, Tracy IC, Strand GM, Singh K, Macaluso M. Survival and drug discontinuation analyses in a large cohort of methotrexate treated rheumatoid arthritis patients. Ann Rheum Dis 1995;54:708-12

17 Bijlsma JW, Oude Heuvel CH, Zaalberg A. Development and validation of the Dutch questionnaire capacities of daily life (VDF) for patients with rheumatoid arthritis. J Rehabil Sci 1990;3:71-4.

18 van der Heijde DM, van Riel PL, Nuver-Zwart IH, Gribnau FW, van de Putte LB. Effects of hydroxychloroquine and sulfasalazine on progression of joint damage in rheumatoid arthritis. Lancet 1989;1:1036-8.

19 Pham B, Cranney A, Boers M, Verhoeven AC, Wells G, Tugwell P. Validity of area-under-the-curve analysis to summarize effect in rheumatoid arthritis clinical trials. J Rheumatol 1999;26:712-16.

20 Matthews JN, Altman DG, Campbell MJ, Royston P. Analysis of serial measurements in medical research. BMJ 1990;300:230-5.

21 Landewe RB, Boers M, Verhoeven AC, et al. COBRA combination therapy in patients with early rheumatoid arthritis: long-term structural benefits of a brief intervention. Arthritis Rheum 2002;46:347-56.

22 Landewe RB, Boers M, Verhoeven AC, Westhovens R, van de Laar MA, Markusse HM, et al. Follow-up radiographic data on patients with rheumatoid arthritis who participated in a two-year trial of prednisone therapy or placebo. Arthritis Rheum 2006;54:1422-8.

23 Grigor C, Capell H, Stirling A, McMahon AD, Lock P, Vallance R, et al. Effect of a treatment strategy of tight control for rheumatoid arthritis (the TICORA study): a single-blind randomised controlled trial. Lancet 2004;364:263-9.

24 Landewe $\mathbf{R}$, van der Heijde D, van der Linden S, Boers M. Twenty-eight-joint counts invalidate the DAS28 remission definition owing to the omission of the lower extremity joints: a comparison with the original DAS remission. Ann Rheum Dis 2006;65:637-41.

25 van der Heijde DM, Jacobs JW. The original "DAS" and the "DAS28" are not interchangeable: comment on the articles by Prevoo et al. Arthritis Rheum 1998;41:942-5.

26 Yazici Y, Sokka T, Kautiainen H, Swearingen C, Kulman I, Pincus T. Long term safety of methotrexate in routine clinical care: discontinuation is unusual and rarely the result of laboratory abnormalities. Ann Rheum Dis 2005;64:207-11

27 Aletaha D, Kapral T, Smolen JS. Toxicity profiles of traditional disease modifying antirheumatic drugs for rheumatoid arthritis. Ann Rheum Dis 2003;62:482-6. 